\title{
Assembly-level analysis of heterogeneous Th-Pu PWR fuel
}

\author{
Nurjuanis Zara Zainuddin, Geoffrey T. Parks*, Eugene Shwageraus \\ Department of Engineering, University of Cambridge \\ Cambridge, CB2 1PZ, United Kingdom \\ Phone: +441223748553 \\ Fax: +44 1223 332662
}

\begin{abstract}
This study compares homogeneous and heterogeneous thorium-plutonium (Th-Pu) fuel assemblies (with high $\mathrm{Pu}$ content - $20 \mathrm{wt} \%$ ), and examines whether there is an increase in $\mathrm{Pu}$ incineration in the latter. A seed-blanket configuration based on the Radkowsky thorium reactor concept is used for the heterogeneous assembly. This separates the thorium blanket from the uranium seed, or in this case a plutonium seed. The seed supplies neutrons to the subcritical thorium blanket which encourages the in-situ breeding and burning of ${ }^{233} \mathrm{U}$, allowing the fuel to stay critical for longer, extending burnup of the fuel.

While past work on Th-Pu seed-blanket units shows superior $\mathrm{Pu}$ incineration compared to conventional $\mathrm{U}-\mathrm{Pu}$ mixed oxide fuel, there is no literature to date that directly compares the performance of homogeneous and heterogeneous Th-Pu assembly configurations. Use of exactly the same fuel loading for both configurations allows the effects of spatial separation to be fully understood.

It was found that the homogeneous fuel with and without burnable poisons were able to achieve much higher $\mathrm{Pu}$ incinerations than the heterogeneous fuel configurations, while still attaining a reasonably high discharge burnup. This is because in the heterogeneous cases, ${ }^{233} \mathrm{U}$ breeding is faster, thereby contributing to a much larger fraction of total power produced by the assembly. In contrast, ${ }^{233} \mathrm{U}$ build-up is slower in the homogeneous case and therefore $\mathrm{Pu}$ burning is greater. This ${ }^{233} \mathrm{U}$ begins to contribute a significant fraction of power produced only towards the end of life, thus extending criticality, allowing more $\mathrm{Pu}$ to burn.
\end{abstract}

Keywords: Thorium, plutonium, heterogeneous fuel, homogeneous fuel, $\mathrm{Pu}$ incineration

\section{Introduction}

Due to significant nuclear proliferation concerns, the incineration or recycling of separated plutonium $(\mathrm{Pu})$, the largest stockpile of which is situated in the UK (Broomby, 2013),

\footnotetext{
*Corresponding author

Email address: gtp10@cam.ac.uk (Geoffrey T. Parks)
} 
has been examined in multiple studies over many years (OECD Nuclear Energy Agency, 1995). Instead of burning Pu in conventional uranium-plutonium mixed oxide (MOX) form (IAEA, 2003; Haas and Hamilton, 2007), which, due to the presence of fertile ${ }^{238} \mathrm{U}$ leads to the production of more $\mathrm{Pu}$, we consider the use of thorium (Th) as a fertile isotope instead. This increases the $\mathrm{Pu}$ incineration rate as additional $\mathrm{Pu}$ is not bred from ${ }^{238} \mathrm{U}$, although fissile ${ }^{233} \mathrm{U}$ is bred instead (Galperin, 1995; Shwageraus et al., 2004a).

While most work on Th-Pu seed-blanket units show that they yield superior $\mathrm{Pu}$ incineration compared to MOX fuel (Galperin et al., 2000), there is no literature to date which directly compares the performance of homogeneous and heterogeneous configurations of pure Th-Pu fuels, i.e. fuels that contain no uranium in its initial loading.

This study explores the possibility of increasing the fraction of $\mathrm{Pu}$ incinerated per pass through a pressurized water reactor (PWR) via the breeding of ${ }^{233} \mathrm{U}$ in a seed-blanket assembly configuration. It is hoped that the ability to generate more ${ }^{233} \mathrm{U}$ from ${ }^{232} \mathrm{Th}$ in heterogeneous configurations will enable a longer and deeper burn of the $\mathrm{Pu}$ present in the fuel. The main mechanism by which this is achieved is physical separation which reduces the competition for neutrons between $\mathrm{Th}$ and $\mathrm{Pu}$, i.e. Th has a better chance of absorbing more neutrons to produce ${ }^{233} \mathrm{U}$ without competition from $\mathrm{Pu}$ isotopes (Shwageraus et al., 2004b).

We limit our heterogeneous analysis to a 3-row blanket assembly and simulate a refuelling scheme (based on the Radkowsky thorium reactor concept) (Galperin et al., 1997, 2000) where the blanket remains in the core three times longer than the seed. The long residence time of the blanket is designed primarily to allow sufficient time for the build-up and in-situ burning of ${ }^{233} \mathrm{U}$.

\section{Model parameters}

The reactor model was based on a standard Westinghouse 3411 MWth 4-loop PWR with 193 fuel assemblies. WIMS 10 (Newton et al., 2008) was used for lattice calculations. The Th-Pu fuel mix used contains $20 \mathrm{wt} \% \mathrm{Pu}$, which is roughly the limit beyond which the full-core moderator temperature coefficient (MTC) becomes prohibitively positive. The reactor-grade Pu isotope vector of PWR spent fuel with a burnup of $33 \mathrm{GWd} / \mathrm{MTU}$ (IAEA, $2003)$ is given in Table 1. Theoretical densities of $95 \%$ are used for $\mathrm{PuO}_{2}$ and $\mathrm{ThO}_{2}-$ $11.5 \mathrm{~g} / \mathrm{cc}$ and $10 \mathrm{~g} / \mathrm{cc}$ respectively. The reduced boron worth due to this high $\mathrm{Pu}$-content fuel necessitated the use of enriched soluble boron $\left(90\right.$ at $\left.\%{ }^{10} \mathrm{~B}\right)$.

To facilitate a fair comparison between the different types of heterogeneous configurations with the homogeneous assemblies in our analysis, exactly the same mass of $\mathrm{Pu}$ is used

Table 1. Plutonium isotope vector.

\begin{tabular}{lccccc}
\hline Isotope & ${ }^{238} \mathbf{P u}$ & ${ }^{239} \mathbf{P u}$ & ${ }^{240} \mathbf{P u}$ & ${ }^{241} \mathbf{P u}$ & ${ }^{242} \mathbf{P u}$ \\
\hline$\%$ & 1.8110 & 59.1380 & 22.9577 & 12.1313 & 3.9620 \\
\hline
\end{tabular}




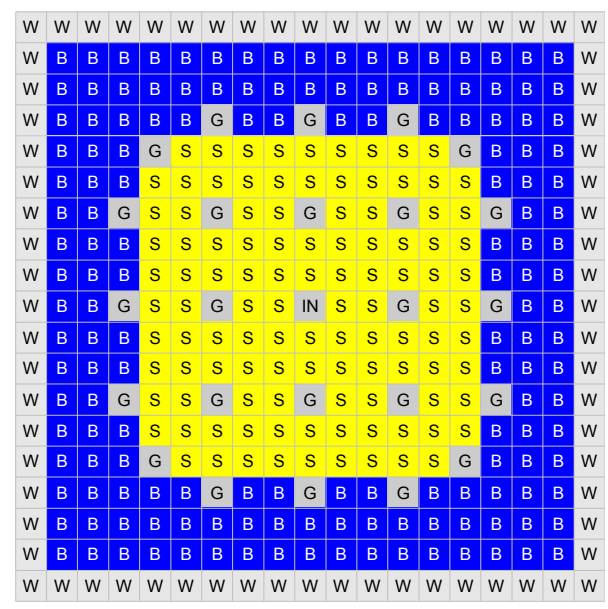

Fig. 1. Geometry of fuel assembly with 3 blanket rows. $\mathrm{S}=$ seed region pin, $\mathrm{B}=$ blanket region pin, $\mathrm{IN}=$ instrumentation tube, $\mathrm{G}$ = guide tube and $\mathrm{W}=$ water gap (not to scale).

throughout, but distributed differently in each assembly region to create heterogeneity. The heterogeneous assembly model is as shown in Fig. 1.

As a full lattice optimization of a seed and blanket assembly configuration is beyond the scope of this work, we have limited our study to:

- Setting the inner region of the assembly as the seed.

- Limiting the number of blanket pin rows to 3, i.e. a seed-to-blanket ratio of 108/156 pins $\approx 40 / 60$, due to thermal-hydraulic considerations discussed by Bromley et al. (2004).

The parameters that we will vary and their effects are:

- Fraction of total Pu mass in the seed (inner) region: This changes the degree of heterogeneity of the assembly. Hence for a fixed amount of $\mathrm{Pu}$, we vary the fraction of total $\mathrm{Pu}$ in the seed region, with the remaining $\mathrm{Pu}$ placed in the blanket region. The respective $\mathrm{Pu}$ content is then homogeneously mixed with pure Th. Note that a $\mathrm{Pu}$ fraction in the seed of 1.0 means that all the $\mathrm{Pu}$ in the assembly is placed in the seed region and the blanket consists entirely of Th. Traditionally, the region with the higher fissile content is defined as the "seed" region and the region with the higher fertile content as the "blanket". As we have designated the inner region of the assembly as the seed, for a 3 blanket row configuration, $\mathrm{Pu}$ fractions in the seed below 0.4 are not analysed as this causes an inversion of the seed and blanket regions.

- Radius of blanket (outer region) pins: As the amount of $\mathrm{Pu}$ is fixed, an increase in blanket pin size increases the amount of Th needed to accommodate the volume increase. This means that the total amount of Th in the assembly will increase compared to the homogeneous cases depending on the size of the pins in the blanket region. The 


\begin{tabular}{|c|c|c|c|c|c|c|c|c|}
\hline \multirow[t]{2}{*}{ Fraction of $\mathrm{Pu}$ in seed region } & \multicolumn{2}{|c|}{0.4} & \multicolumn{2}{|c|}{0.6} & \multicolumn{2}{|c|}{0.8} & \multicolumn{2}{|c|}{1} \\
\hline & \multicolumn{8}{|c|}{$\mathrm{wt} \% \mathrm{Pu}$ in region } \\
\hline Blanket pin radius $(\mathrm{cm})$ & $\mathrm{S}$ & $\mathrm{B}$ & $\mathrm{S}$ & $\mathrm{B}$ & $\mathrm{S}$ & $\mathrm{B}$ & $\mathrm{S}$ & $\mathrm{B}$ \\
\hline 0.4095 & 19.57 & 20.30 & 28.98 & 13.65 & 38.16 & 6.89 & 47.11 & 0.00 \\
\hline 0.45 & 19.57 & 16.89 & 28.98 & 11.34 & 38.16 & 5.71 & 47.11 & 0.00 \\
\hline 0.5 & 19.57 & 13.74 & 28.98 & 9.21 & 38.16 & 4.63 & 47.11 & 0.00 \\
\hline
\end{tabular}

Table 2. Summary of analysed cases ( $\mathrm{S}=$ seed region and $\mathrm{B}=$ blanket region).

seed pin size is kept constant at $0.4095 \mathrm{~cm}$. Increasing the blanket pin size also affects the hydrogen-to-heavy-metal ratio of this region.

The different configurations of the heterogeneous assemblies are shown in Table 2, which give the wt\% of $\mathrm{Pu}$ in the different seed or blanket regions. The table divides the compositions based on the fraction of $\mathrm{Pu}$ in the seed, which we will refer to as Cases $0.4 \mathrm{Pu}$ up to $1 \mathrm{Pu}$. As mentioned, the total amount of $\mathrm{Pu}$ is fixed in all the investigated cases, therefore it can be seen from Table 2 that for each Case, the wt\% of $\mathrm{Pu}$ in the seed region does not change as seed pin size remains constant, compared to the blanket region which decreases with an increase in blanket pin size.

The heterogeneous assembly configurations will be benchmarked against homogeneously mixed Th-Pu fuel with $20 \mathrm{wt} \% \mathrm{Pu}$. We also include homogeneous fuel with integral fuel burnable absorbers (IFBA) of thickness $0.004 \mathrm{~cm}$ containing $50 \mathrm{wt} \%{ }^{10} \mathrm{~B}$ on all pins. Analysis by the same authors (Zainuddin et al., 2016), found that these give reasonable values for maximum radial form factors and MTC in a full-core setting. These fuels will be simply referred to as "Homogeneous" and "Homogeneous + IFBA".

Note that this is a purely reactor physics study. The practicality (in terms of, for example, materials and thermal-hydraulic performance) of designs judged successful from this perspective will, of course, need further consideration.

\section{Results}

\subsection{Reactivity}

Fig. 2 shows the criticality curves for seed Cycle 1, for 4 different assembly configurations with $\mathrm{Pu}$ fractions in the seed varying from 0.4 up to 1.0 (Case $0.4 \mathrm{Pu}$ to $1 \mathrm{Pu}$ ) with a blanket pin size of $0.4095 \mathrm{~cm}$.

It can be seen that for Cases $0.8 \mathrm{Pu}$ and below, the criticality curves behave similarly to that of the homogeneous fuel. However, for Case $1 \mathrm{Pu}$, we see that there is a reactivity hold-down at the beginning of life, which indicates increased breeding of ${ }^{233} \mathrm{U}$ from neutron captures in Th. The reactivity is then higher than the homogeneous case from a burnup of $40 \mathrm{GWd} / \mathrm{MT}$ onwards, which indicates fissioning of this bred fuel thus achieving a higher discharge burnup. 


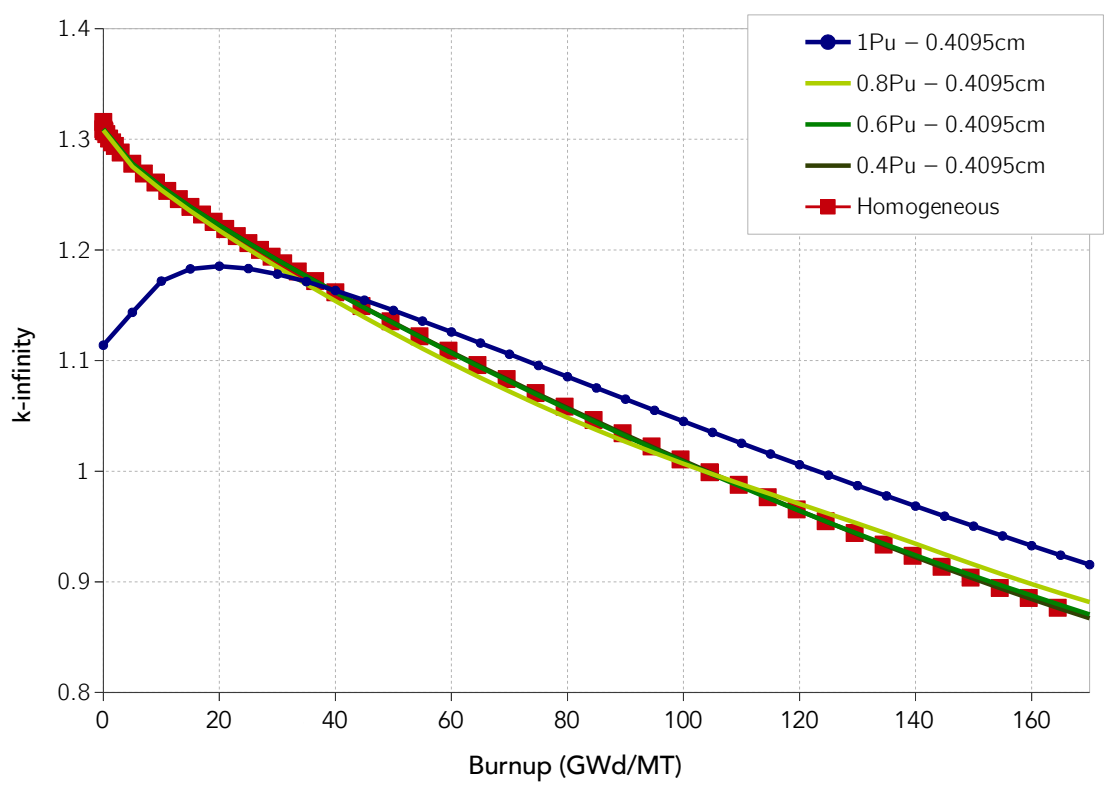

Fig. 2. $k_{\infty}$ curves for seed Cycle 1, for $\mathrm{Pu}$ fractions in the seed of 0.4 to 1.0 for a blanket pin size of $0.4095 \mathrm{~cm}$.

Note that, as shown in Table 2, the blanket for Case $1 \mathrm{Pu}$ is comprised purely of $\mathrm{Th}$, compared to Case $0.8 \mathrm{Pu}$ which contains $6.89 \mathrm{wt} \% \mathrm{Pu}$. The difference in reactivity behaviour is due to the flux redistribution effect caused by the strongly absorbing $\mathrm{Pu}$, and will be explained in detail in Sections 3.2.1 and 3.4.1.

This behaviour is also seen for the two other $1 \mathrm{Pu}$ cases with blanket fuel pin sizes of 0.45 and $0.5 \mathrm{~cm}$ in Fig. 3. However, there is a slight decrease in criticality, relative to the standard case with a blanket fuel pin size of $0.4095 \mathrm{~cm}$.

To understand this decrease, we examine the evolution of $\mathrm{Pu}$ and ${ }^{233} \mathrm{U}$ in the assembly. While blanket pin size marginally affects the amount of ${ }^{239} \mathrm{Pu}$ burnt (Fig. 4a), Fig. 4b shows that increasing the pin size increases the amount of ${ }^{233} \mathrm{U}$ that is created. The reasons for this are:

- Increasing blanket pin size increases the Th content in the assembly, which increases the capture rate in $\mathrm{Th}$ and breeding of ${ }^{233} \mathrm{U}$.

- A larger pin size decreases moderation (i.e. hardens the neutron spectrum). ${ }^{232} \mathrm{Th}$ is an epithermal absorber (Fig. 5), so a harder spectrum results in a higher capture rate in Th and subsequent ${ }^{233} \mathrm{U}$ breeding. Conversely, ${ }^{233} \mathrm{U}$ is a thermal absorber, which means the harder spectrum reduces ${ }^{233} \mathrm{U}$ fission. Hence the ${ }^{233} \mathrm{U}$ in the blanket is less effective while the large amount of $\mathrm{Th}$ in the larger blanket pins acts as a constant neutron sink.

This explains the consistently lower criticality throughout the cycle for blanket fuel pin sizes of 0.45 and $0.5 \mathrm{~cm}$ compared to the standard pin size of $0.4095 \mathrm{~cm}$ (Fig. 3), as the fatter 


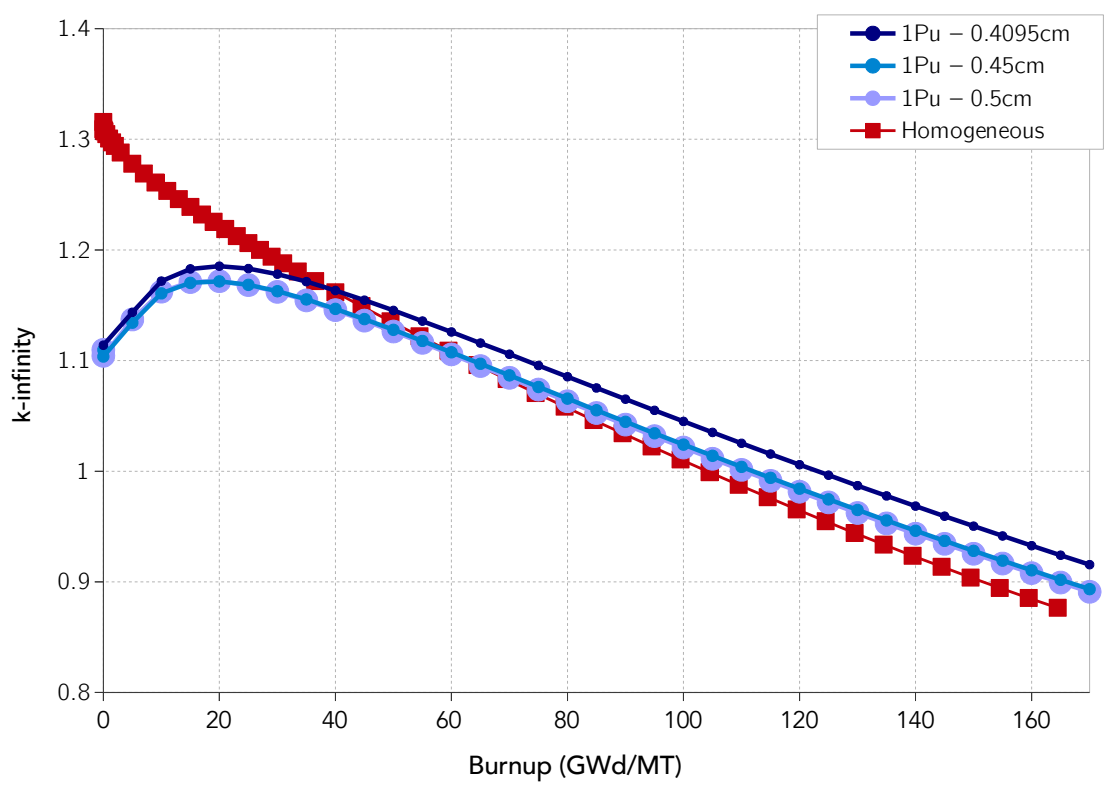

Fig. 3. $k_{\infty}$ curves for seed Cycle 1, for 3 blanket pin sizes for a Pu fraction in the seed of 1.0.

blanket pins create ${ }^{233} \mathrm{U}$ but do not burn it as efficiently. Hence, if our primary objective was to breed ${ }^{233} \mathrm{U}$ as fissile material for use in future reactors, then heterogeneous assemblies are viable options for achieving this.

\subsection{Moderator temperature coefficient}

One of the big constraints with Th-Pu fuel, especially for high concentrations of $\mathrm{Pu}$, is MTC. For this reason, we analysed the MTC of each assembly in Table 2. As a simplification, the lattice-level MTC calculation performed was for fresh fuel, i.e. at start of life. This is not an unreasonable reference point for MTC, as from previous experience (Zainuddin et al. 2016), the core MTC was limited by the MTC of the fresh fuel.

To confirm this behaviour, a full-core burnup cycle was executed for Case 1Pu with a standard out-in core loading pattern. Full-core calculations were carried out using PANTHER (Hutt et al., 1991; Parks and Knight, 1995), a general-purpose whole reactor code that solves the multi-group neutron diffusion equation with coupled thermal and poison feedback. The core MTC was found to be highest at the start of cycle, and decreased monotonically, as shown in Fig. 6. Note that Fig. 6] shows the variation of MTC with the core-average burnup of the fresh, once- and twice-burnt fuel in the core for an equilibrium cycle.

For this study, the lattice-level MTC was calculated under "core-average critical boron" conditions, which is simply a batch-averaged critical boron concentration (CBC) (Fig. 7a). Fig. $7 \mathrm{~b}$ shows the resulting MTC as a function of the fraction of $\mathrm{Pu}$ in the inner region.

Three things can be observed from Fig. 77:

- There appears to be an inverse relationship between MTC and boron concentration, 


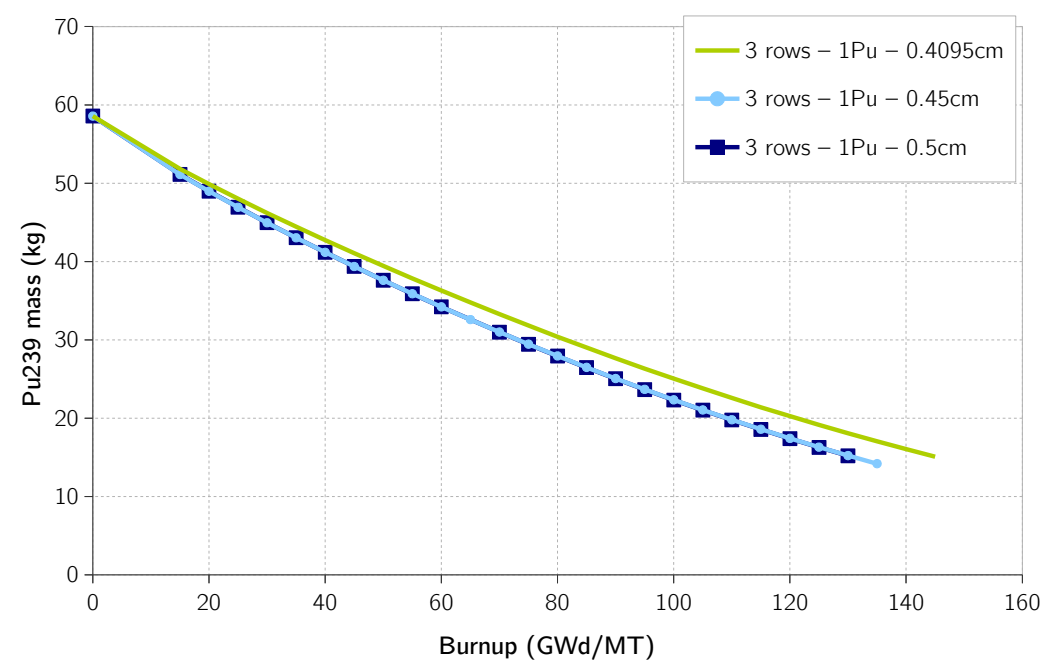

(a) ${ }^{239} \mathrm{Pu}$

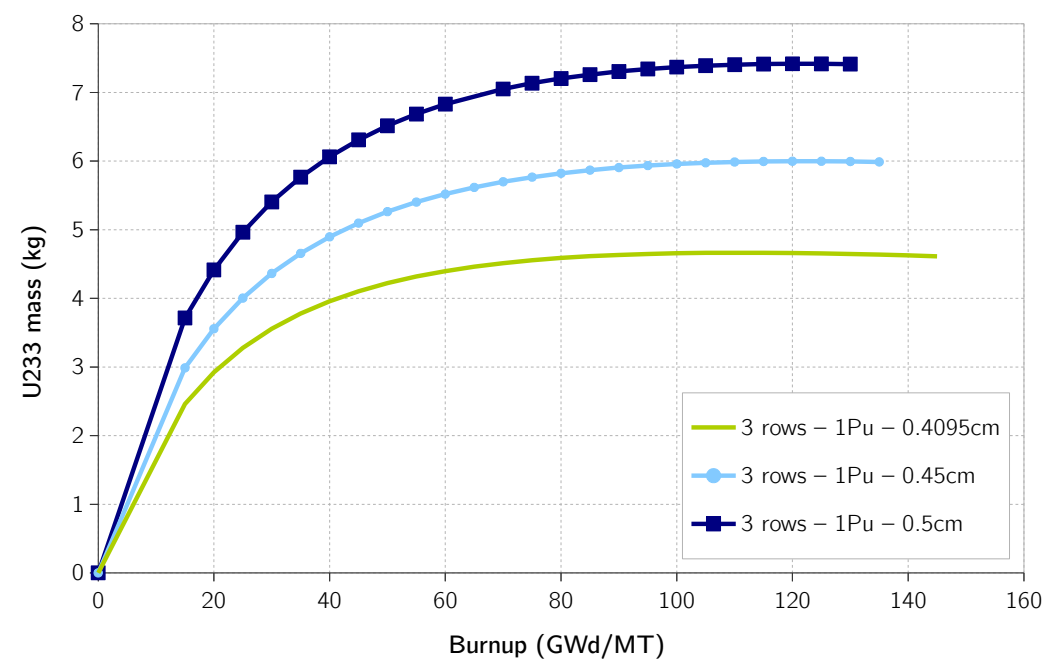

(b) ${ }^{233} \mathrm{U}$

Fig. 4. Mass evolution of (a) ${ }^{239} \mathrm{Pu}$ and (b) ${ }^{233} \mathrm{U}$ in an assembly for different blanket pin sizes for a $\mathrm{Pu}$ fraction in the seed of 1.0 . 


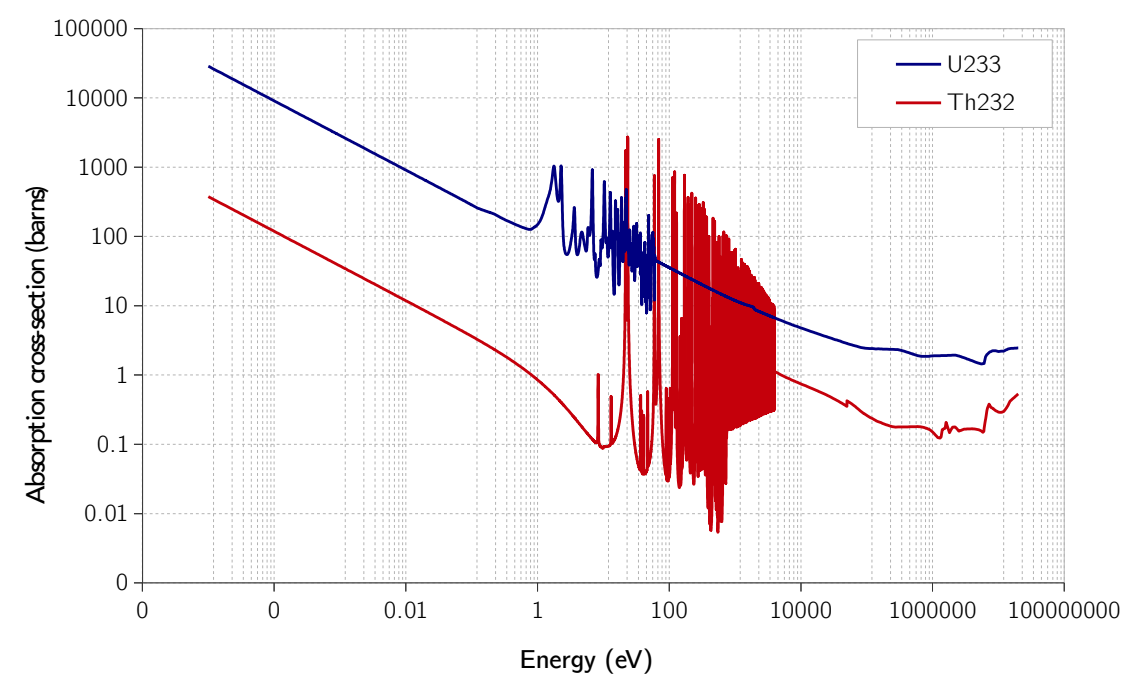

Fig. 5. ${ }^{232} \mathrm{Th}$ and ${ }^{233} \mathrm{U}$ absorption cross-sections.

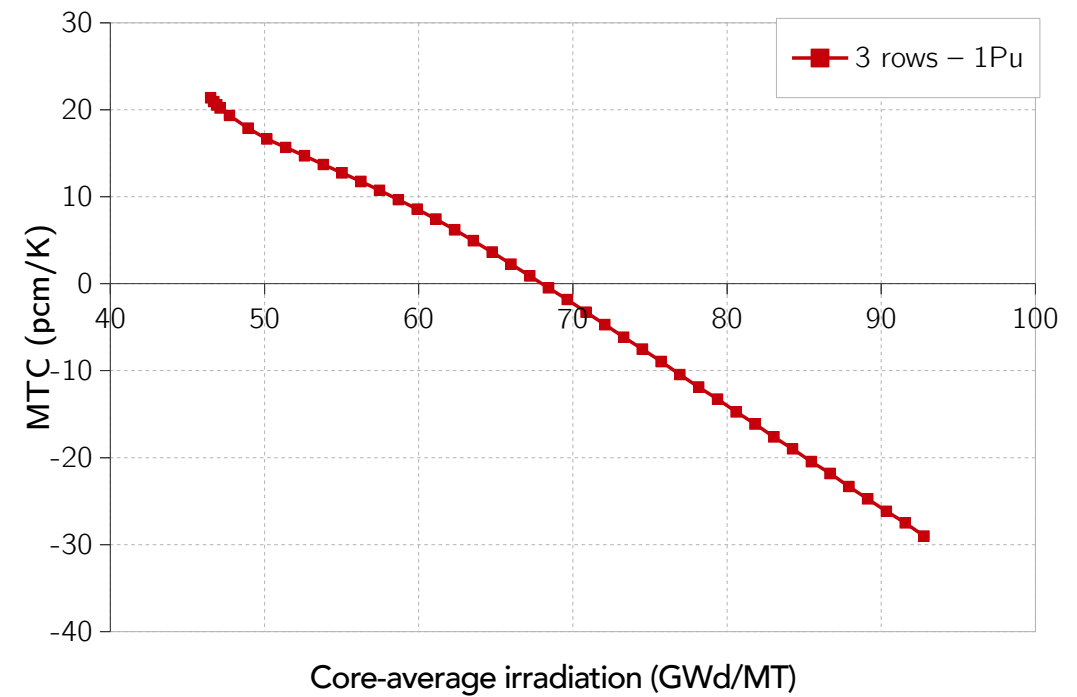

Fig. 6. Core MTC for Case 1Pu with a standard out-in core loading pattern.

which runs counter to the conventional wisdom that MTC becomes more negative with a reduction in boron concentration.

- For cases which have a Pu fraction in the seed of 1.0 (Case $1 \mathrm{Pu}$ ), the MTC is positive and almost twice the magnitude of the MTC for the other $\mathrm{Pu}$ fraction cases.

- For Cases $0.4 \mathrm{Pu}$ to $0.8 \mathrm{Pu}$ with a blanket pin radius of $0.4095 \mathrm{~cm}$ (i.e. all pins in the assembly are the same size), their MTC and CBC are almost identical to those for the homogeneous case.

The observation that the MTC and critical boron for Cases $0.4 \mathrm{Pu}-0.8 \mathrm{Pu}$ are similar to 


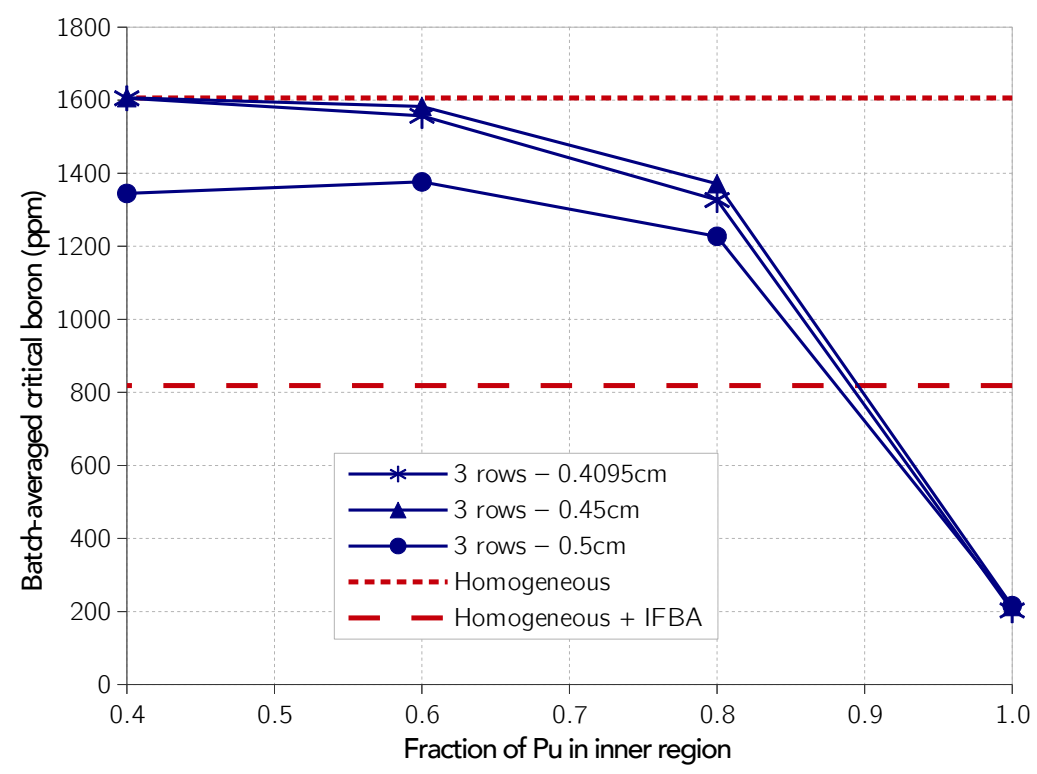

(a) Batch-average critical boron.

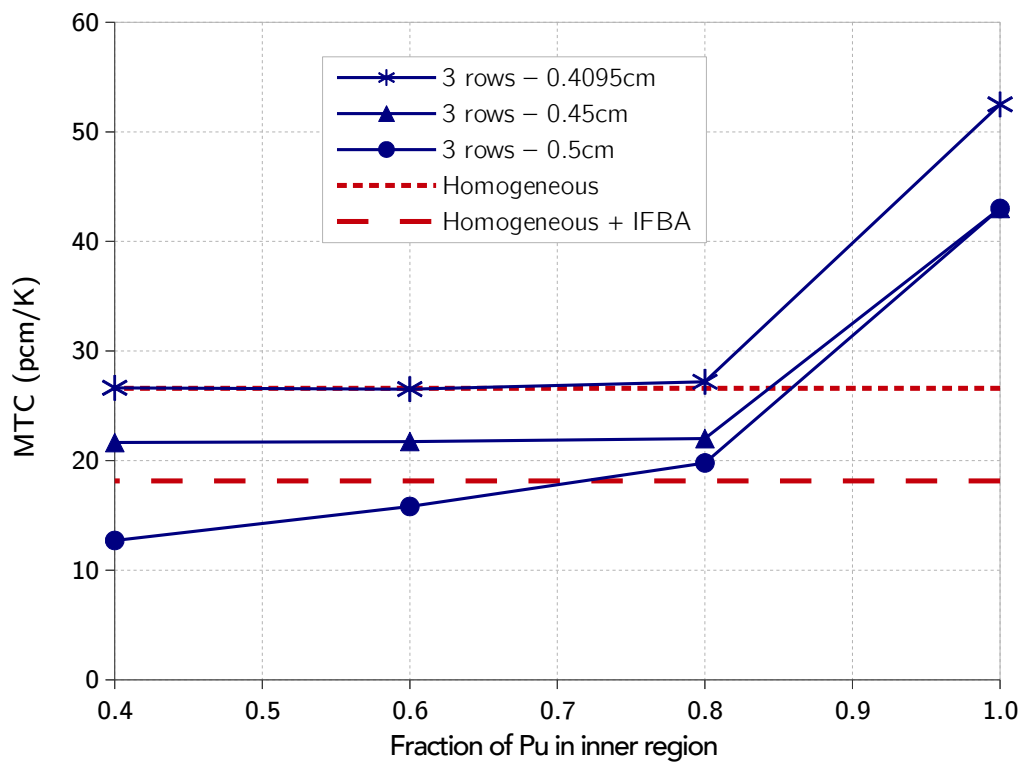

(b) MTC of fresh fuel.

Fig. 7. MTC of fresh fuel at batch-average critical boron for a varying fraction of $\mathrm{Pu}$ in the seed region and different blanket pin sizes. 
the homogeneous case is expected, since the $k_{\infty}$ curves in Fig. 2 are almost identical to the homogeneous case. The assembly with a blanket pin radius of $0.5 \mathrm{~cm}$ has a slightly lower value of MTC, which decreases with decreasing $\mathrm{Pu}$ fraction in the seed. The exact reason for this effect was not investigated in this work. However, one of the most likely explanations could be the fact that $\mathrm{Pu}$-containing lattices are very sensitive to moderation because of the strong thermal absorption and complex resonance structure (meaning that the effect could also be sensitive to the $\mathrm{Pu}$ isotopic mix). The blanket moderator-to-fuel ratio change is much larger when moving from a pin radius of 0.45 to $0.5 \mathrm{~cm}$ than when moving from 0.41 to $0.45 \mathrm{~cm}$. Therefore, the blanket region spectral change, and thus the corresponding whole assembly MTC response, is much more pronounced for the $0.50 \mathrm{~cm}$ blanket pin case. The results of our study also show that increasing the blanket region dimensions from 2 rows to 4 rows amplifies the effect seen in Fig. 7. This observation supports the above hypothesis, because a large blanket would mean a larger proportion of the assembly is affected by the blanket region-average asymptotic spectrum and is thus sensitive to its perturbation.

With regards to $\mathrm{MTC}$, for Case $1 \mathrm{Pu}$, a smaller $\mathrm{CBC}$ is required due to the reactivity hold-down at the start of life (Fig. 2). Despite this, the MTC does not reduce accordingly, but is, in fact, twice the value of the other cases. As the MTC increases sharply between Pu fractions of 0.8 and 1.0, we found it instructive to dissect these cases further, as per Table 3 , and find the corresponding values for MTC, shown in Fig. 8. Compared to Case 1Pu, a Pu fraction of 0.9 (Case $0.9 \mathrm{Pu}$ ) seems promising, as its MTC increases only very slightly from the homogeneous case. We will discuss its viability in the coming sections.

\begin{tabular}{|c|c|c|c|c|c|c|c|c|c|c|}
\hline \multirow[t]{2}{*}{ Fraction of $\mathrm{Pu}$ in seed } & \multicolumn{2}{|c|}{0.9} & \multicolumn{2}{|c|}{0.95} & \multicolumn{2}{|c|}{0.99} & \multicolumn{2}{|c|}{0.995} & \multicolumn{2}{|c|}{0.9975} \\
\hline & \multicolumn{10}{|c|}{ wt $\% \mathrm{Pu}$ in region } \\
\hline Blanket pin radius $(\mathrm{cm})$ & $\mathrm{S}$ & $\mathrm{B}$ & $\mathrm{S}$ & $\mathrm{B}$ & S & B & $\mathrm{S}$ & B & $\mathrm{S}$ & B \\
\hline 0.4095 & 42.66 & 3.46 & 44.90 & 1.73 & 46.67 & 0.35 & 46.89 & 0.17 & 47.00 & 0.09 \\
\hline 0.45 & 42.66 & 2.87 & 44.90 & 1.44 & 46.67 & 0.29 & 46.89 & 0.14 & 47.00 & 0.07 \\
\hline 0.5 & 42.66 & 2.32 & 44.90 & 1.16 & 46.67 & 0.23 & 46.89 & 0.12 & 47.00 & 0.06 \\
\hline
\end{tabular}

Table 3. High $\mathrm{Pu}$ seed region fraction cases examined ( $\mathrm{S}=$ seed region and $\mathrm{B}=$ blanket region).

\subsubsection{Understanding effects on $M T C$}

Positive MTC for Th-Pu fuel was originally thought to be due to the large soluble boron concentrations needed to maintain criticality for fuel with high $\mathrm{Pu}$ content. However, an investigation into the contributors to positive MTC by the same authors (Zainuddin et al., 2016) using the methods of Ganda and Greenspan (2010) shows that the key factor is, in fact, increased fissioning in the epithermal-fast energy range.

Thus, to understand the MTC behaviour seen so far in our heterogeneous assemblies, we compare two cases:

1. Case $1 \mathrm{Pu}: 100 \%$ of total $\mathrm{Pu}$ in seed, pure Th blanket $-\mathrm{MTC}=52.5 \mathrm{pcm} / \mathrm{K}$ 


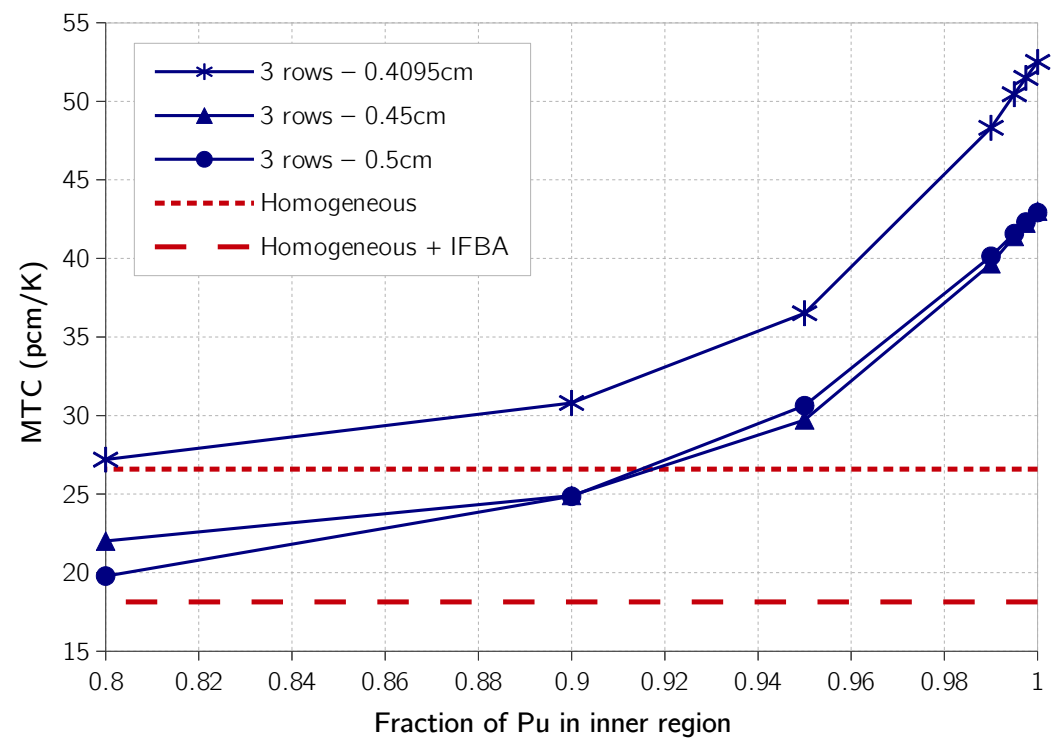

Fig. 8. MTC as a function of $\mathrm{Pu}$ seed region fraction.

2. Case $0.8 \mathrm{Pu}: 80 \%$ of total $\mathrm{Pu}$ in seed $-\mathrm{MTC}=27.2 \mathrm{pcm} / \mathrm{K}$

Using the method of identifying individual contributions to MTC from (Ganda and Greenspan, 2010), the system $k_{\infty}$ is broken down by isotope and energy group and by normalizing "per absorbed neutron". The resulting MTC contributions by isotope for Cases $1 \mathrm{Pu}$ and $0.8 \mathrm{Pu}$ are shown in Fig. 9. Note that the summation of each component by isotope equals the total MTC. The main difference between the two cases is found to be in the contribution of ${ }^{239} \mathrm{Pu}$.

We then investigate the partial MTC contribution of ${ }^{239} \mathrm{Pu}$ over the energy spectrum, as shown in Fig. 10. As identified in a previous study (Zainuddin et al., 2016), the main contribution to positive MTC of high Pu content fuel comes from increased fission in the epithermal region of the spectrum. However, the main difference between Cases $1 \mathrm{Pu}$ and $0.8 \mathrm{Pu}$ is at energy levels of $1 \mathrm{eV}$ and below. In Case $0.8 \mathrm{Pu}$, there is more negative contribution to the MTC compared to Case $1 \mathrm{Pu}$, which has a positive contribution at $0.3 \mathrm{eV}$.

Further examining the flux spectra for the seed and blanket for both cases in Fig. 11, it is apparent that the blanket for Case $1 \mathrm{Pu}$ has a large thermal peak. As the blanket consists purely of thorium, the neutrons that are slowed down by the moderator have a better chance of fully thermalizing, unlike Case $0.8 \mathrm{Pu}$ where the plutonium present in the blanket $(20 \%$ of the total $\mathrm{Pu}$ mass) absorbs many of the thermalizing neutrons.

A close-up of the seed spectra superimposed on the ${ }^{239} \mathrm{Pu}$ and ${ }^{241} \mathrm{Pu}$ resonances at $\sim 0.3 \mathrm{eV}$ and ${ }^{240} \mathrm{Pu}$ resonance at $\sim 1 \mathrm{eV}$ is shown in Fig. 12. Case $1 \mathrm{Pu}$ has $100 \% \mathrm{Pu}$ in its seed and Case $0.8 \mathrm{Pu}$ has only $80 \% \mathrm{Pu}$ in its seed, hence one might expect that the thermal flux would be lower for Case 1Pu. However, this is not necessarily the case, as seen in Fig. 12. The spectrum for Case $1 \mathrm{Pu}$ to the left of the $0.3 \mathrm{eV}{ }^{239} \mathrm{Pu}$ resonance is, in fact, higher than the spectrum for Case $0.8 \mathrm{Pu}$. For Case $1 \mathrm{Pu}$, this is due to the influx of thermal neutrons from the large thermal spectrum peak in its blanket, as shown in Fig. 11. However, beyond 


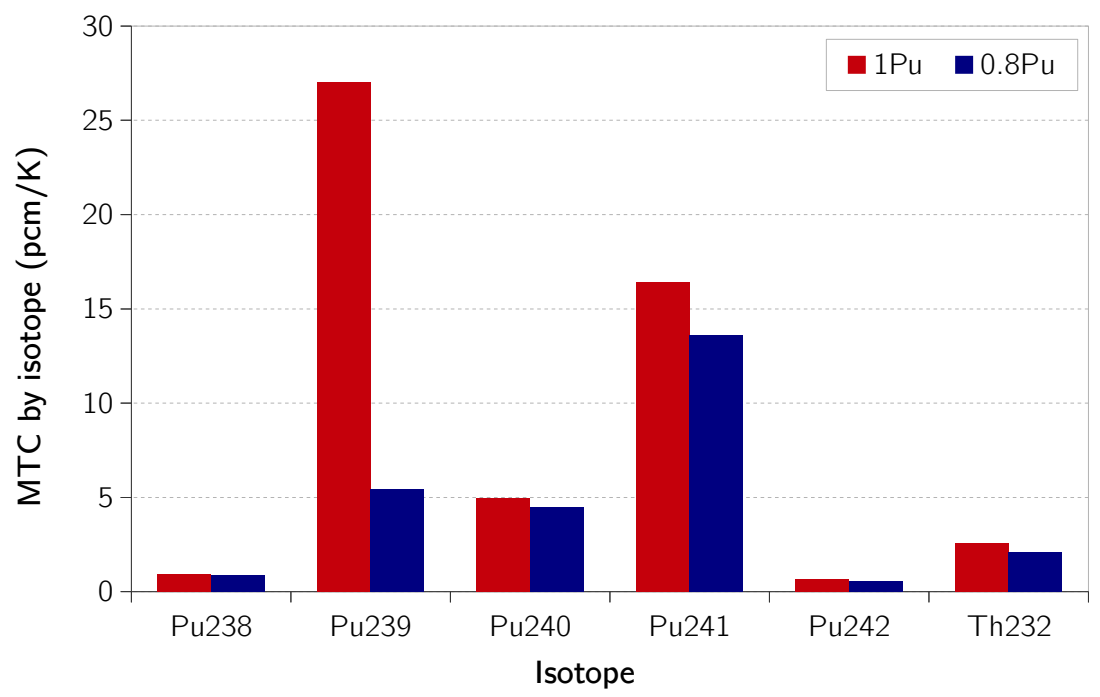

Fig. 9. MTC contributions by isotope, where MTC for Case $1 \mathrm{Pu}=52.5 \mathrm{pcm} / \mathrm{K}$ and Case $0.8 \mathrm{Pu}=$ $27.2 \mathrm{pcm} / \mathrm{K}$.

$0.3 \mathrm{eV}$, the flux for Case $1 \mathrm{Pu}$ is lower than that of Case $0.8 \mathrm{Pu}$ due to its higher content of ${ }^{240} \mathrm{Pu}$, which has a large absorption resonance at $\sim 1 \mathrm{eV}$.

In examining the numbers, the positive contribution to MTC of ${ }^{239} \mathrm{Pu}$ at $0.3 \mathrm{eV}$ can be traced to an increase in the absorption reaction rate for ${ }^{239} \mathrm{Pu}$ in Case $1 \mathrm{Pu}$, and a decrease for Case $0.8 \mathrm{Pu}$. The presence of the ${ }^{239} \mathrm{Pu}$ resonance here greatly amplifies any slight changes in spectrum caused by the influx of thermal neutrons from blanket to seed, due to the complete absence of plutonium in the blanket in Case $1 \mathrm{Pu}$.

\subsection{Refuelling}

The objective of spatially separating seed and blanket is to allow the separate refuelling of the seed region in a single assembly. As mentioned, the blanket will remain in the core three times longer than the seed to allow the build-up of ${ }^{233} \mathrm{U}$, enabling the discharge burnup of the fuel to be increased.

We simulate refuelling by burning an assembly until it reaches its discharge burnup, the value of which is found using the linear reactivity model (Driscoll et al., 1991) for a simple 3-batch refuelling scheme. At this point, the seed is taken out, and a fresh seed is placed in the assembly with the once-burnt blanket, and this is repeated for a total of 3 seed cycles, i.e. 3 seed loadings. However, as the half-life of ${ }^{233} \mathrm{~Pa}$ is 27 days, a refuelling time of about one month will mean that, at the start of each refuelled cycle, the blanket will contain bred ${ }^{233} \mathrm{U}$ (from the previous cycle) plus about half of the bred ${ }^{233} \mathrm{~Pa}$ that has decayed into ${ }^{233} \mathrm{U}$ during the refuelling outage.

Fig. 13 shows the criticality curves for 3 cycles of the heterogeneous fuel (fresh seed + fresh blanket, fresh seed + once-burn blanket, fresh seed + twice-burnt blanket) for Cases $0.4 \mathrm{Pu}$ to $1 \mathrm{Pu}$ with pin size of $0.4095 \mathrm{~cm}$. The homogeneous assembly that is used as a 


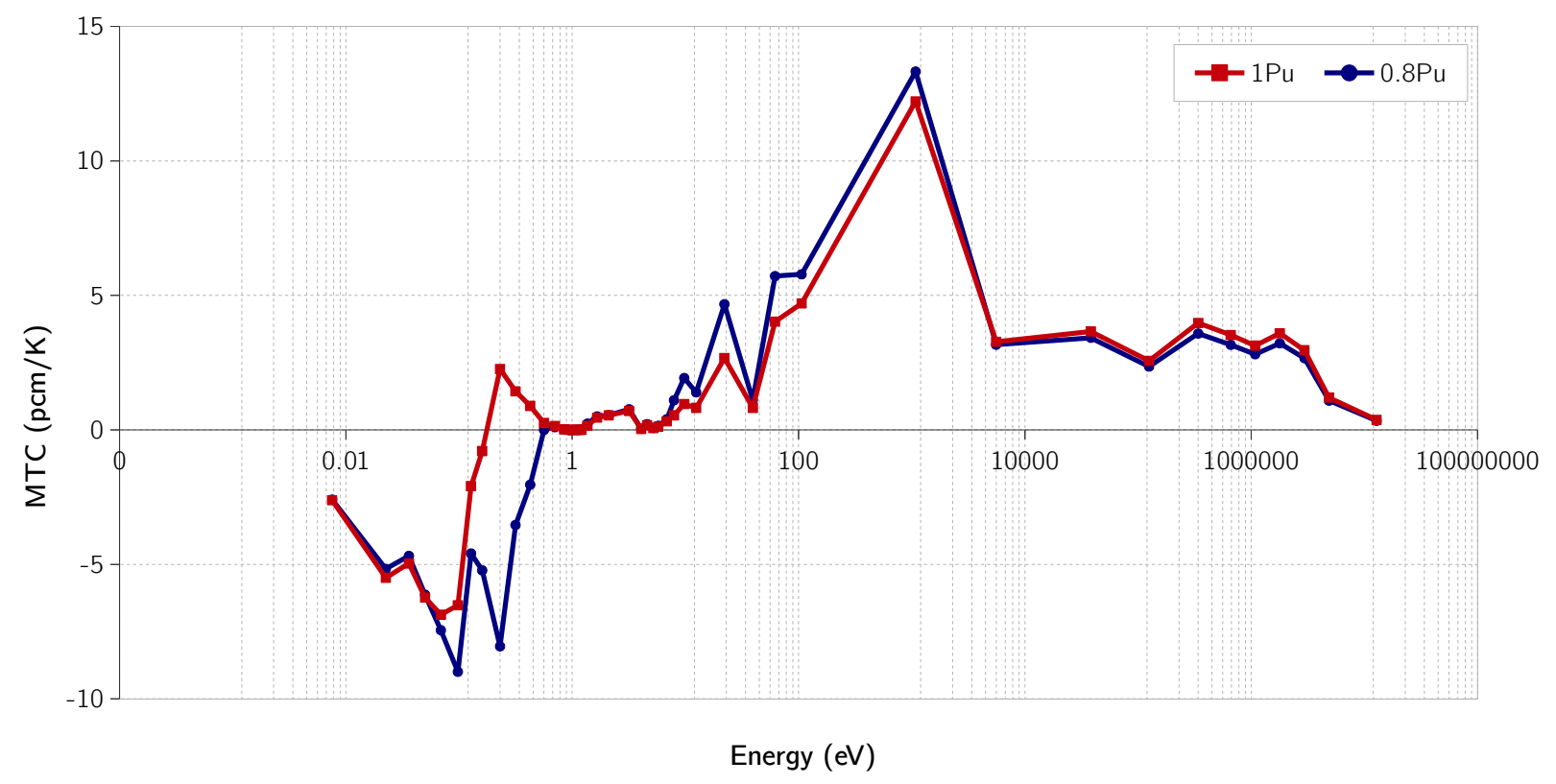

Fig. 10. MTC contribution of ${ }^{239} \mathrm{Pu}$ over the energy spectrum. The total contribution of ${ }^{239} \mathrm{Pu}$ to $\mathrm{MTC}$ for Case $1 \mathrm{Pu}=27.01 \mathrm{pcm} / \mathrm{K}$ and for Case $0.8 \mathrm{Pu}=5.44 \mathrm{pcm} / \mathrm{K}$.

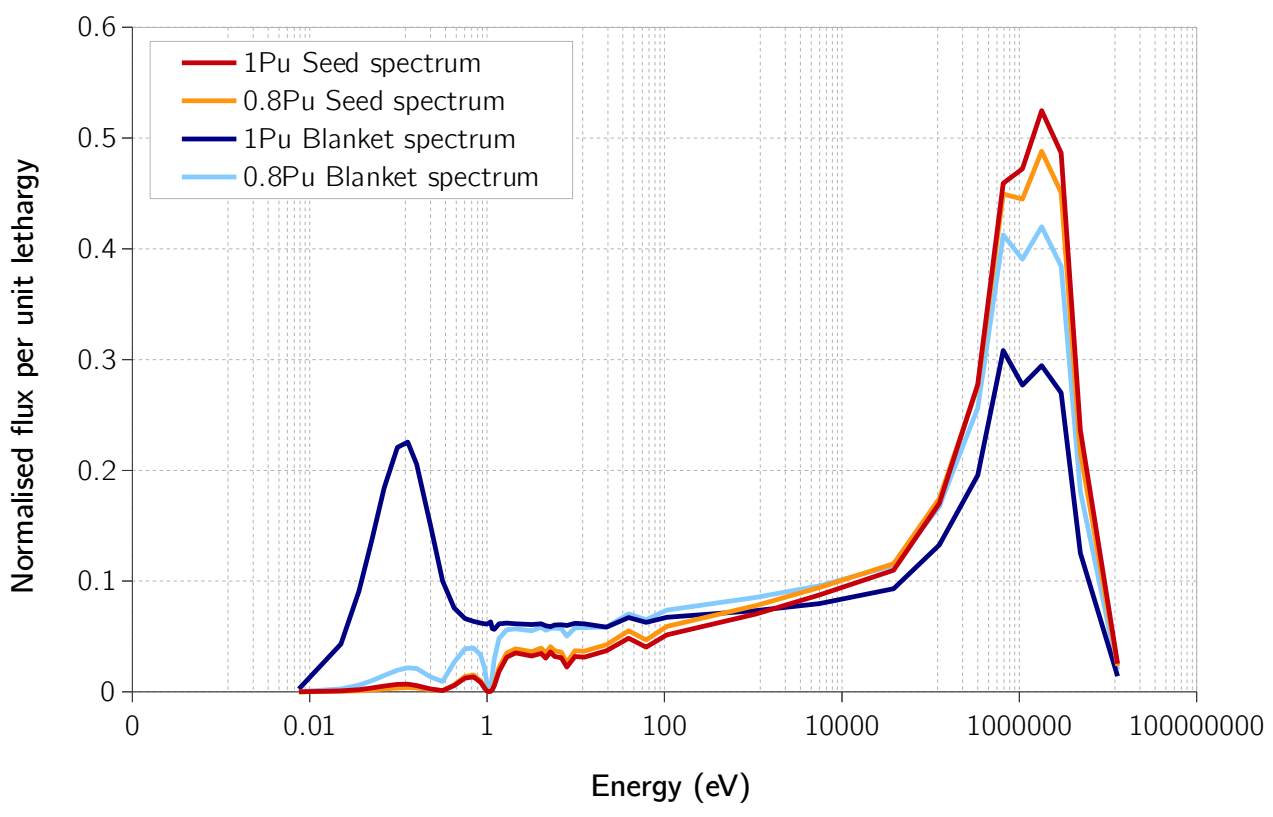

Fig. 11. Flux spectra in the seed and blanket for Cases $1 \mathrm{Pu}$ and $0.8 \mathrm{Pu}$.

benchmark is not refuelled, and therefore its cycle length $L_{\mathrm{Hom}}$ is roughly equivalent to only one cycle of the heterogeneous assemblies, i.e. $L_{\mathrm{Het}}=3 L_{\mathrm{Hom}}$.

As mentioned earlier, for ease of comparison with the homogeneous case, we load exactly 


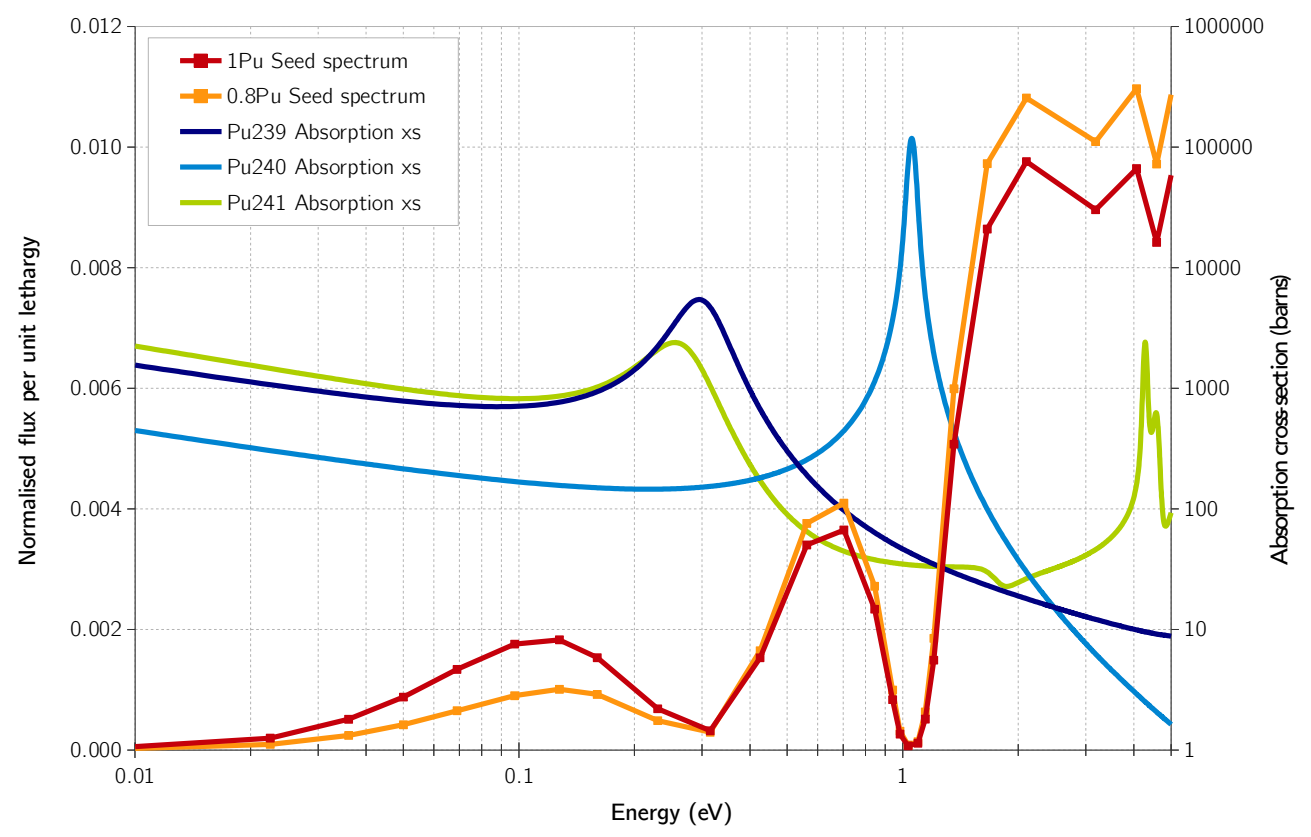

Fig. 12. Close-up of the seed flux spectra for Cases $1 \mathrm{Pu}$ and $0.8 \mathrm{Pu}$ superimposed on the ${ }^{239} \mathrm{Pu},{ }^{240} \mathrm{Pu}$ and ${ }^{241} \mathrm{Pu}$ absorption cross-sections.

the same mass of $\mathrm{Pu}$ in the heterogeneous assembly $\left(M_{\mathrm{Pu}-\mathrm{Hom}}=M_{\mathrm{Pu}-\mathrm{Het}}\right)$, but redistributed the $\mathrm{Pu}$ in the seed $\left(M_{\mathrm{Pu}-\mathrm{S}}\right)$ and blanket $\left(M_{\mathrm{Pu}-\mathrm{B}}\right)$, respectively, where $M_{\mathrm{Pu}-\mathrm{Het}}=M_{\mathrm{Pu}-\mathrm{S}}+M_{\mathrm{Pu}-\mathrm{B}}$. However, this means that the amount of $\mathrm{Pu}$ loaded into the assembly at start of the second and third cycles will not be $M_{\mathrm{Pu}-\mathrm{Het}}$ anymore, but instead is dependent on the mass of $\mathrm{Pu}$ in the seed $\left(M_{\mathrm{Pu}-\mathrm{S}}\right)$ that is loaded. Therefore the total amount of $\mathrm{Pu}$ loaded into the assembly for the 3 cycles is $M_{\mathrm{Pu}-\mathrm{Het}}, M_{\mathrm{Pu}-\mathrm{S}}$ and $M_{\mathrm{Pu}-\mathrm{S}}$, respectively.

The expectation in using this reloading scheme was that, by the end of the first cycle, enough ${ }^{233} \mathrm{U}$ would have been bred in the blanket to compensate for the depletion of $\mathrm{Pu}$ and help maintain criticality. However, as can be seen in Fig. 13, this is not the case. For all cases excluding Case $1 \mathrm{Pu}$ (where full $M_{\mathrm{Pu} \text {-Het }}$ is reloaded at every cycle), there is not enough ${ }^{233} \mathrm{U}$ bred in the blanket to sustain criticality beyond the first cycle. This means that we require a $\mathrm{Pu}$ fraction close to that of Case $1 \mathrm{Pu}$ but without the burden of the large positive MTC seen previously. Based on Fig. 8, we find a suitable compromise in Case $0.9 \mathrm{Pu}$. Plotting its $k_{\infty}$ curves for 3 cycles in Fig. 14, Case $0.9 \mathrm{Pu}$ shows slight potential gains in cycle length over the homogeneous assembly, indicative of ${ }^{233} \mathrm{U}$ burning towards the end of life, and is a reasonable representative of a heterogeneous assembly to compare with the benchmark homogeneous case.

\section{4. ${ }^{239} \mathrm{Pu}$ incineration and ${ }^{233} \mathrm{U}$ breeding over 3 refuelling cycles}

Having settled on a $\mathrm{Pu}$ fraction that will give reasonable MTC and discharge burnup for 3 cycles, we now examine whether a heterogeneous assembly is able to breed more ${ }^{233} \mathrm{U}$ and hence incinerate more ${ }^{239} \mathrm{Pu}$ than a homogeneous assembly. As mentioned in the previous section, we replace the seed pins every seed cycle, for 3 cycles. Thus, we sum the ${ }^{239} \mathrm{Pu}$ 


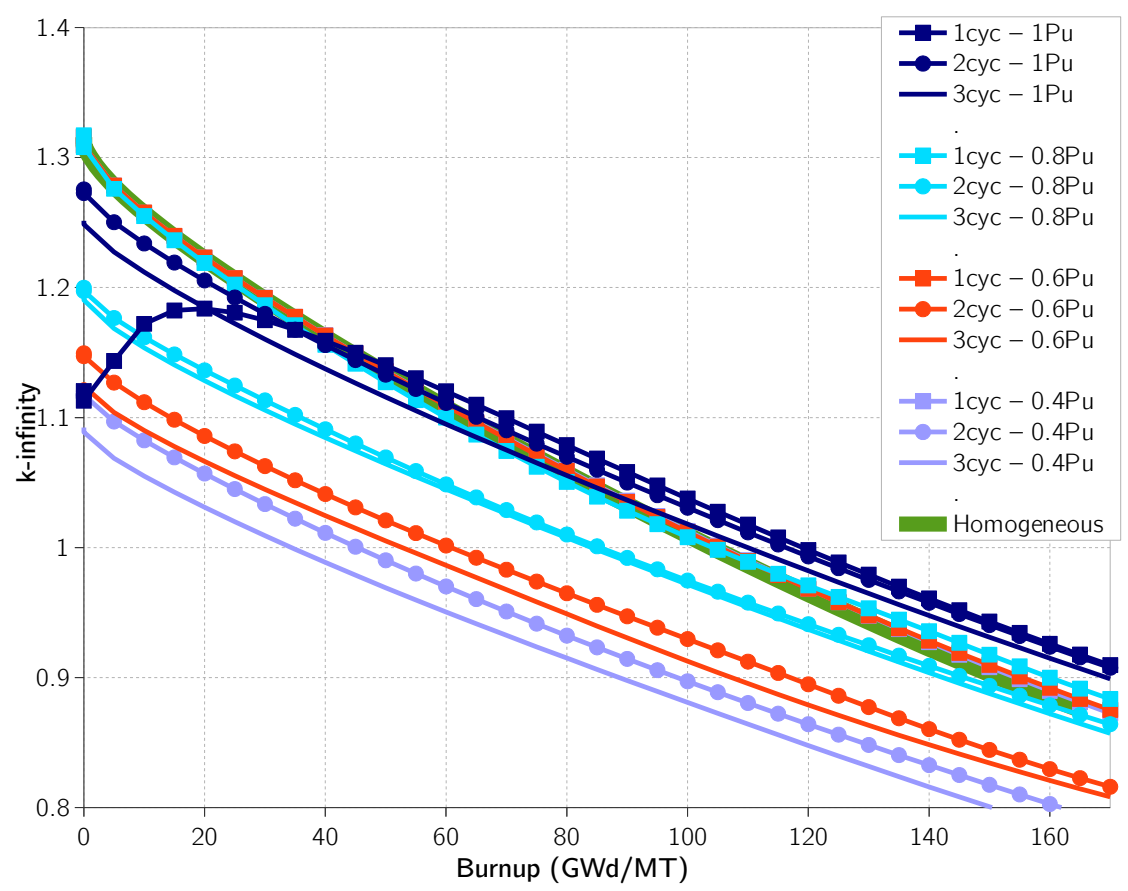

Fig. 13. $k_{\infty}$ for 3 cycles for a single assembly that is refuelled with a new seed region every cycle for various $\mathrm{Pu}$ fractions in the seed.

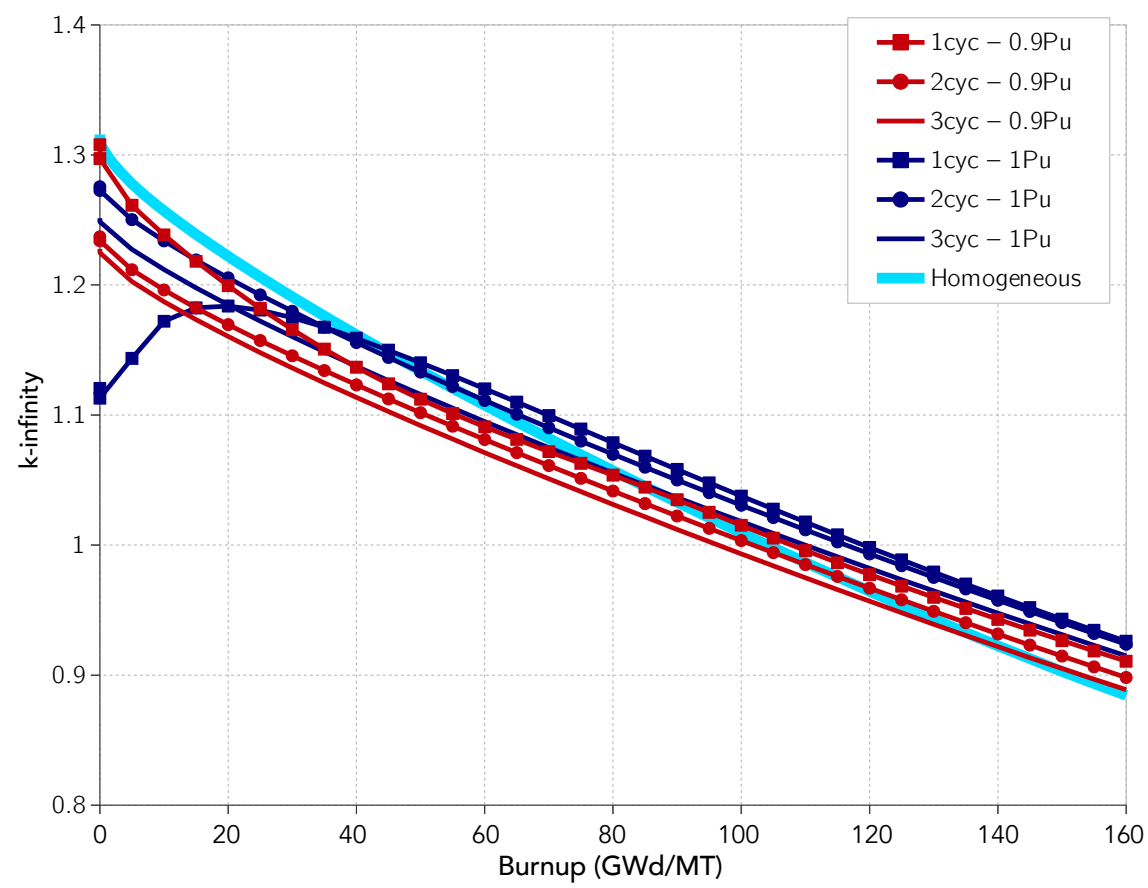

Fig. 14. $k_{\infty}$ for 3 cycles for a single assembly that is refuelled with a new seed region every cycle for $\mathrm{Pu}$ fractions in the seed of 0.9 and 1.0 . 
mass incinerated and ${ }^{233} \mathrm{U}$ mass created in 3 seed batches and 1 blanket batch over the 3 cycles mentioned. On the other hand, for the homogeneous case, we multiply these values for one complete cycle burnup by 3, to match the 3 refuelling cycles of the heterogeneous assemblies. Fig. 15a shows that the heterogeneous assemblies do poorly compared to the simple homogeneous case, with and without BPs. Table 4 shows the mass of ${ }^{239} \mathrm{Pu}$ and total $\mathrm{Pu}$ incinerated in an assembly in each case.

Note that increasing the blanket pin size increases the ${ }^{233} \mathrm{U}$ that is created, which remains at the end of cycle (Fig. 15b). As mentioned earlier in Section 3.1, a larger pin size decreases moderation. This harder spectrum is more conducive for capture in ${ }^{232} \mathrm{Th}$ and subsequent breeding of ${ }^{233} \mathrm{U}$ but not for the fissioning of ${ }^{233} \mathrm{U}$.

As a point of comparison, Fridman (2009) analysed $\mathrm{MgO}-\mathrm{ZrO}_{2}$ inert matrix fuel with varying combinations of $\mathrm{BPs}\left(\mathrm{Er}_{2} \mathrm{O}_{3}, \mathrm{HfO}_{2}\right.$, WABAs and IFBAs) for $\mathrm{Pu}$ content from 8 to $10 \mathrm{vol} \%$, and found that between 83.27 and $94.95 \%$ of the initial ${ }^{239} \mathrm{Pu}$ loading can be incinerated. This is similar to our homogeneous case (Fig. 15a) and even better than the cases we have analysed in this study. However, without the presence of fertile fuel, inert matrix fuels suffer from inferior Doppler coefficients. Additionally, with no breeding of fissile material and the need for BPs to manage reactivity, such fuel have shorter cycle lengths.

\begin{tabular}{lccc}
\hline Cases & ${ }^{239} \mathbf{P u}(\mathbf{k g})$ & $\mathbf{P u}(\mathrm{kg})$ & $\mathbf{\%} \mathbf{P u}$ \\
\hline Homogeneous & 152.04 & 179.43 & 60.39 \\
Homogeneous + IFBA & 151.43 & 178.76 & 60.17 \\
$1 \mathrm{Pu}-0.4095 \mathrm{~cm}$ & 119.72 & 136.72 & 46.00 \\
$1 \mathrm{Pu}-0.45 \mathrm{~cm}$ & 122.47 & 140.58 & 47.30 \\
$1 \mathrm{Pu}-0.5 \mathrm{~cm}$ & 120.43 & 138.16 & 46.48 \\
$0.9 \mathrm{Pu}-0.4095 \mathrm{~cm}$ & 110.02 & 127.47 & 45.84 \\
$0.9 \mathrm{Pu}-0.45 \mathrm{~cm}$ & 110.93 & 128.96 & 46.34 \\
$0.9 \mathrm{Pu}-0.5 \mathrm{~cm}$ & 110.24 & 128.37 & 46.15 \\
\hline
\end{tabular}

Table 4. Mass of ${ }^{239} \mathrm{Pu}$ and mass and percentage of total $\mathrm{Pu}$ incinerated over 3 blanket cycles, i.e. 3 seed reloadings, for various cases.

\subsubsection{Homogeneous vs heterogeneous Pu incineration}

Finally, we analyse the effects of spatial separation of the seed and blanket of a heterogeneous assembly as compared to a homogeneous assembly. To establish a fair comparison between the two, we artificially divide the homogeneous assembly into inner and outer regions, having the same number of pins as the heterogeneous case $1 \mathrm{Pu}$ (Fig. 1). Table 5 reminds us of the fuel composition in each region.

Comparing the fission reaction rates between these inner and outer regions and then summing them gives us Fig. 16. Note that Fig. 16 only shows the seed Cycle 1 for the heterogeneous case. First, we look at the incineration or fissioning of ${ }^{239} \mathrm{Pu}$ in Fig. 16a. The outer region of Case $1 \mathrm{Pu}$ consists of pure $\mathrm{Th}$, so there are no reactions in ${ }^{239} \mathrm{Pu}$. However, in the seed, which contains all of the $\mathrm{Pu}$ mass, the reaction rate is higher than in either region 


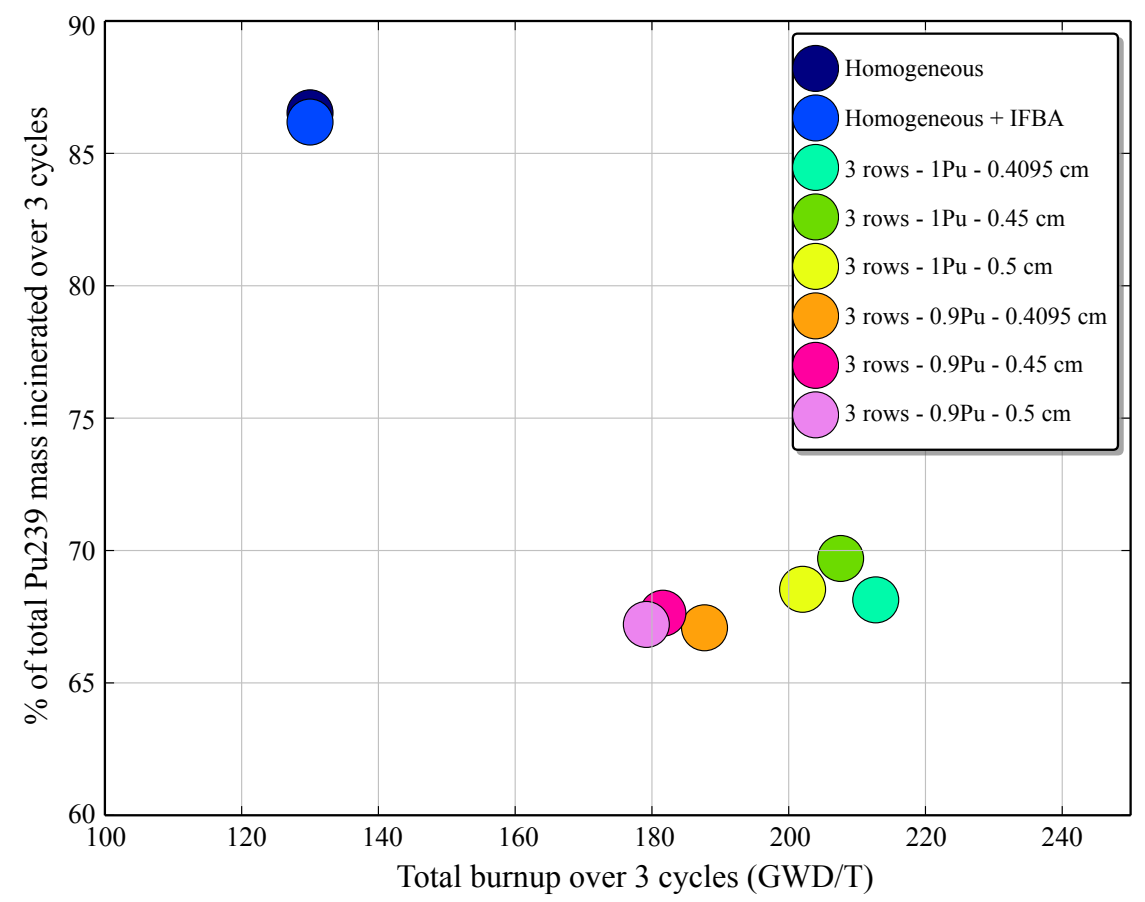

(a) Percentage of ${ }^{239} \mathrm{Pu}$ mass incinerated.

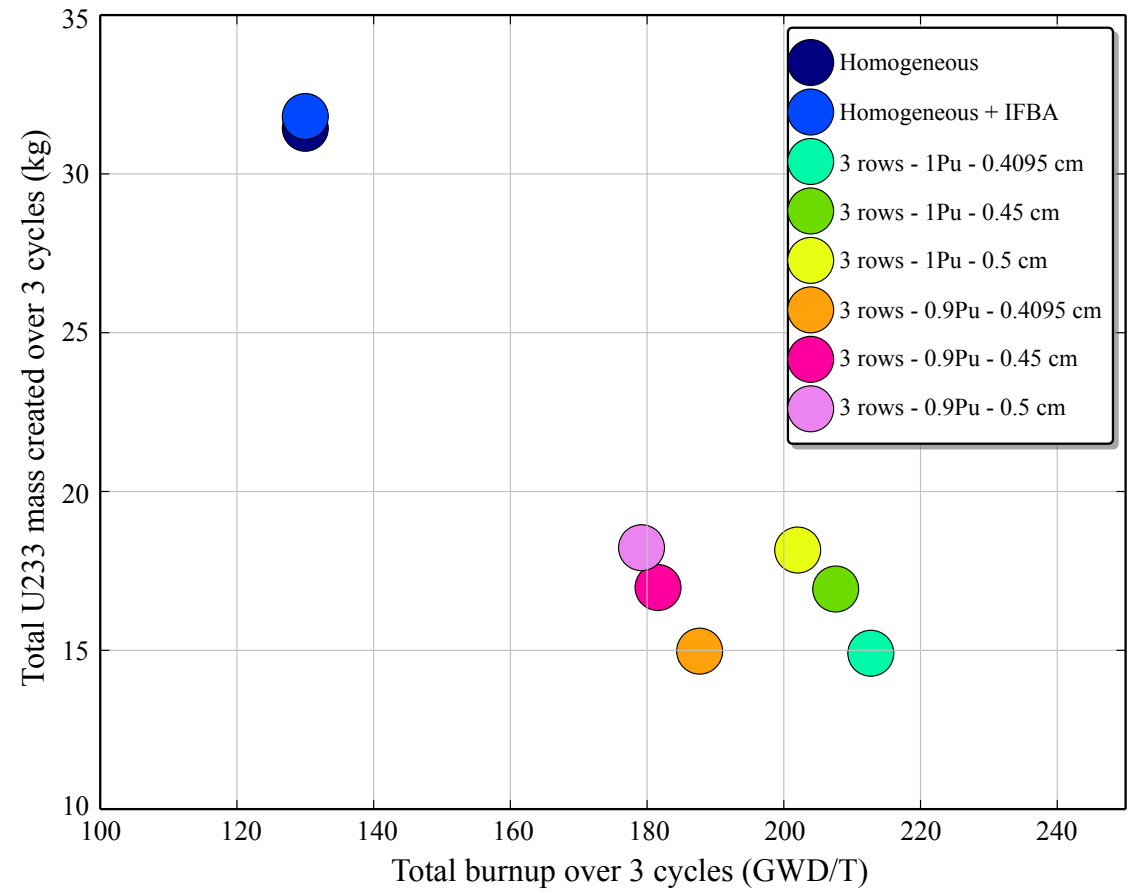

(b) Total mass of ${ }^{233} \mathrm{U}$ bred.

Fig. 15. Percentage of initial ${ }^{239} \mathrm{Pu}$ mass incinerated and total mass of ${ }^{233} \mathrm{U}$ bred after 3 seed cycles. 


\begin{tabular}{lcc}
\hline Case & Inner region & Outer region \\
\hline $1 \mathrm{Pu}$ & 47.11 & 0 \\
Homogeneous & 20 & 20 \\
\hline
\end{tabular}

Table 5. Wt\% of plutonium in each region for the $1 \mathrm{Pu}$ and homogeneous cases.

of the homogeneous case. Conversely, ${ }^{233} \mathrm{U}$ is able to breed more efficiently in the outer region (blanket) of Case $1 \mathrm{Pu}$ due to the absence of competition with $\mathrm{Pu}$ for neutrons. This, along with having a more thermal spectrum than the seed, allows ${ }^{233} \mathrm{U}$ to readily fission.

In the homogeneous case, however, while the ${ }^{239} \mathrm{Pu}$ fission reaction rates are lower than the $1 \mathrm{Pu}$ case, this process is happening in both inner and outer regions, as opposed to just the inner region for Case $1 \mathrm{Pu}$. At the same time, ${ }^{233} \mathrm{U}$ is slowly being bred and fissioned, but at a slower rate than in Case $1 \mathrm{Pu}$ (Fig. 16b).

The summation of these effects is shown in Fig. $16 \mathrm{c}$. For the homogeneous case, ${ }^{239} \mathrm{Pu}$ dominates power share for most of the fuel's life, thus incinerating more $\mathrm{Pu}$, as compared to Case $1 \mathrm{Pu}$ where the power shifts to ${ }^{233} \mathrm{U}$ quite early on. The inventories of both isotopes for one seed cycle are shown in Fig. 17, where we see clearly that the homogeneous case incinerates more $\mathrm{Pu}$ than the heterogeneous case. Note that the homogeneous case accumulates more ${ }^{233} \mathrm{U}$ at the end of its life, as shown in Fig. $17 \mathrm{~b}$.

Thus, to conclude, it was hoped that the breeding of ${ }^{233} \mathrm{U}$ in the heterogeneous assembly would extend the discharge burnup of the fuel, giving it a "deeper burn" of $\mathrm{Pu}$. As we saw earlier in Figs. 13 and 14, the discharge burnup is higher compared to the homogeneous case. However, for the heterogeneous case, the power share of ${ }^{233} \mathrm{U}$ is dramatically higher. Therefore, there still remains more $\mathrm{Pu}$ that has not been burnt, but not enough to sustain criticality. In contrast, for the homogeneous case, $\mathrm{Pu}$ has a much larger power share for most of the cycle, while slowly building ${ }^{233} \mathrm{U}$ in the background. This ${ }^{233} \mathrm{U}$ then fissions towards the end of the cycle, allowing the incineration of remaining $\mathrm{Pu}$ that cannot otherwise sustain criticality on its own. This behaviour is the "deeper burn" of $\mathrm{Pu}$ that we initially were hoping to achieve with the heterogeneous case, but instead have achieved with a homogeneous assembly configuration.

\section{Summary and Conclusions}

This study examines whether heterogeneous fuel assembly configurations are able to increase $\mathrm{Pu}$ incineration. The spatial separation of the thorium blanket from the plutonium seed allows the breeding and burning of ${ }^{233} \mathrm{U}$ in the blanket, which we hoped would increase burnup, allowing for a deeper burn of Pu.

While past work on $\mathrm{Th}-\mathrm{Pu}$ seed-blanket units shows superior plutonium incineration compared to MOX fuel, there is no literature to date which directly compares the performance of homogeneous and heterogeneous $\mathrm{Th}-\mathrm{Pu}$ configurations. Setting the fuel loadings for both configurations to be equal allowed us to properly understand the effects of spatial separation. 


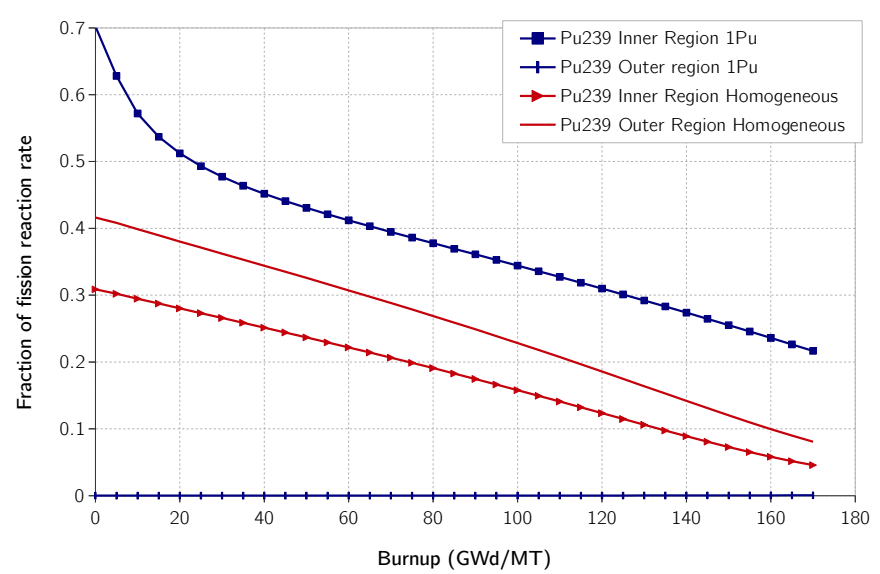

(a) ${ }^{239} \mathrm{Pu}$

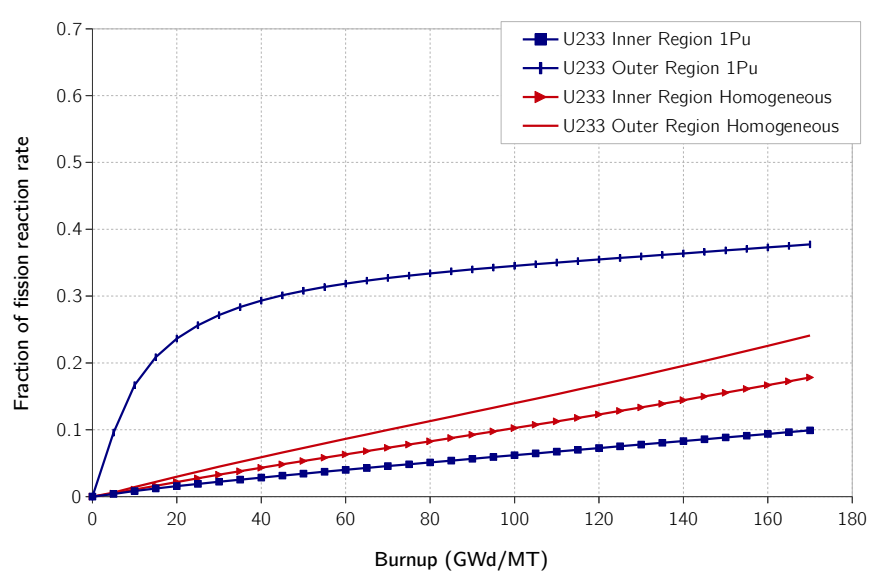

(b) ${ }^{233} \mathrm{U}$

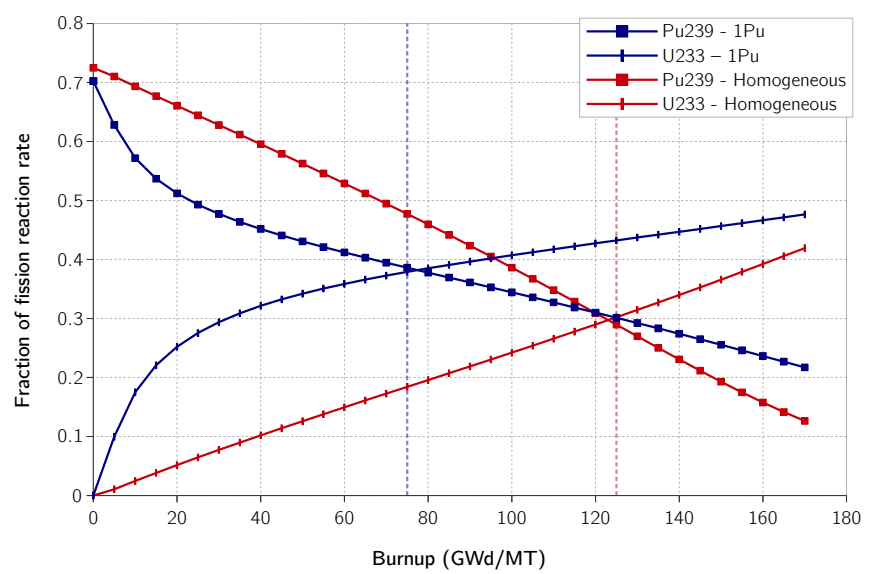

(c) Summation of reaction rates for the whole assembly. The dotted lines show the points at which power share in the assembly shifts from ${ }^{239} \mathrm{Pu}$ to ${ }^{233} \mathrm{U}$.

Fig. 16. Fraction of fission reaction rate by isotope for inner and outer region of assembly. 


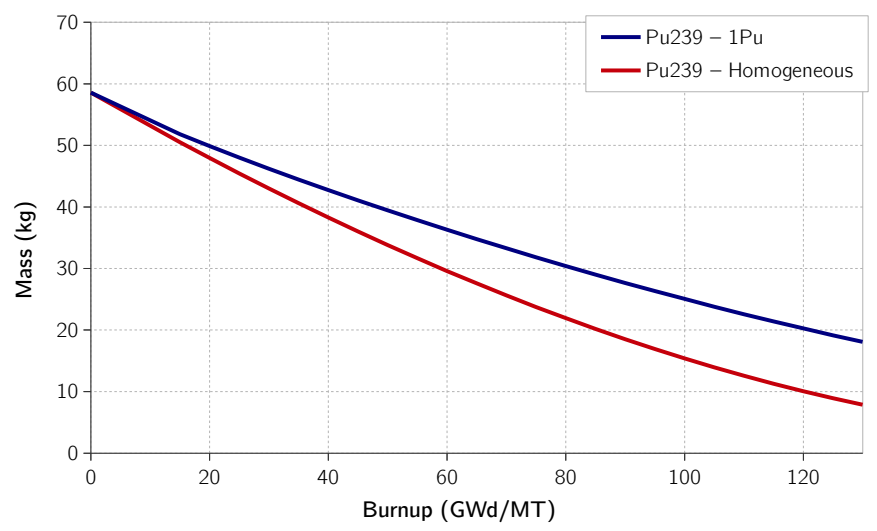

(a) ${ }^{239} \mathrm{Pu}$

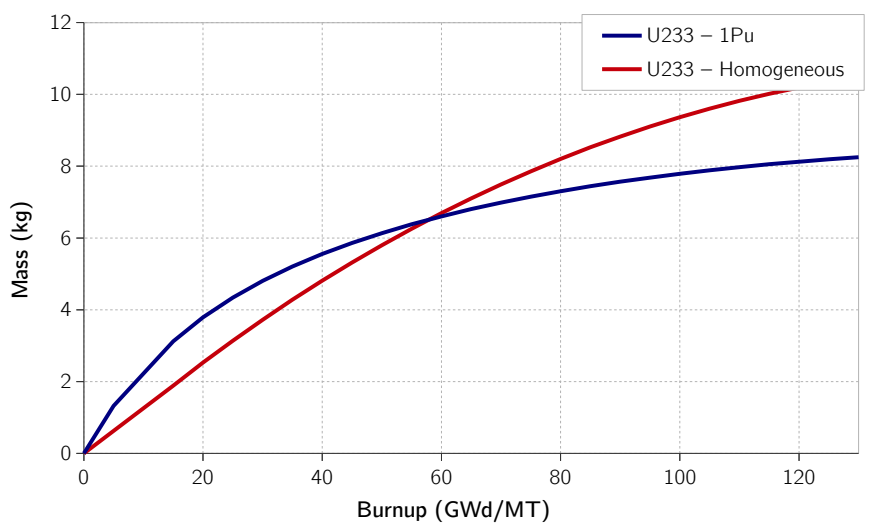

(b) ${ }^{233} \mathrm{U}$

Fig. 17. Variation with burnup of ${ }^{239} \mathrm{Pu}$ and ${ }^{233} \mathrm{U}$ mass in Case $1 \mathrm{Pu}$ compared to a homogeneous assembly. 
We showed that the homogeneous fuel with and without BPs incinerated more plutonium than its heterogeneous counterparts. This is because, while heterogeneous assemblies efficiently bred ${ }^{233} \mathrm{U}$, they also burnt it at the same time. In contrast, the homogeneous case rapidly burns $\mathrm{Pu}$ while slowly breeding ${ }^{233} \mathrm{U}$, which only starts burning towards the end of life. This behaviour, in fact, utilises ${ }^{233} \mathrm{U}$ when it is needed most, i.e. burning when the remaining $\mathrm{Pu}$ cannot sustain criticality and extending burnup to incinerate $\mathrm{Pu}$ left in the assembly. This deep burn of $\mathrm{Pu}$ is what was initially assumed to be achieved in heterogeneous assemblies, but instead is found to be efficiently executed in homogeneous fuel.

If breeding ${ }^{233} \mathrm{U}$ for use in future reactors was the primary objective, then a heterogeneous assembly not only allows easy extraction, but larger diameter blanket pins can increase the amount of ${ }^{233} \mathrm{U}$ bred.

It must be reiterated that these conclusions apply to high $\mathrm{Pu}$ content (20 wt\%) Th-Pu fuel that is capable of driving the homogeneous fuel to such high burnups where these advantages are realised. For lower $\mathrm{Pu}$ loadings, the homogeneous and heterogeneous configurations have comparable performance, but the heterogenous assemblies would be more complicated and difficult to cool. Thus, this work can be viewed as another justification for using high $\mathrm{Pu}$ content homogeneous fuel, as it allows the benefit of simple manufacturing (of homogeneous fuel) as well as better $\mathrm{Pu}$ incineration.

\section{Acknowledgements}

The first author is grateful for the financial support of Yayasan Tenaga Nasional, Malaysia.

\section{References}

Bromley, B., Todosow, M., Aronson, A., Galperin, A., 2004. Optimization studies for seed-and-blanket unit (SBU) fuel assemblies in PWRs, in: Proc. PHYSOR 2004, Chicago, IL.

Broomby, R., 2013. UK's Plutonium Stockpile Dilemma. URL: http://www.bbc.co.uk/news/ uk-21505271.

Driscoll, M.J., Downar, T.J., Pilat, E.E., 1991. The Linear Reactivity Model for Nuclear Fuel Management. American Nuclear Society, La Grange Park, IL.

Fridman, E., 2009. Fertile Free Fuels in LWRs - Core Physics and Cycle Options. Ph.D. thesis. Ben-Gurion University of the Negev. Beer-Sheva, Israel.

Galperin, A., 1995. Utilization of light water reactors for plutonium incineration. Ann. Nucl. Energy 22, $507-511$.

Galperin, A., Reichert, P., Radkowsky, A., 1997. Thorium fuel for light water reactors - reducing proliferation potential of nuclear power fuel cycle. Sci. Global Sec. 6, 265-290.

Galperin, A., Segev, M., Todosow, M., 2000. A pressurized water reactor plutonium incinerator based on thorium fuel and seed-blanket assembly geometry. Nucl. Technol. 132, 214-226.

Ganda, F., Greenspan, E., 2010. Analysis of reactivity coefficients of hydride-fueled PWR cores. Nucl. Sci. Eng. 164, 1-32.

Haas, D., Hamilton, D.J., 2007. Fuel cycle strategies and plutonium management in Europe. Prog. Nucl. Energy 49, 574-582.

Hutt, P.K., Gaines, N., Halsall, M.J., McEllin, M., White, R.J., 1991. The UK core performance code package. Nucl. Energy 30, 291-298.

IAEA, 2003. Potential of Thorium Based Fuel Cycles to Constrain Plutonium and Reduce Long Lived Waste Toxicity. Technical Report IAEA-TECDOC-1349. International Atomic Energy Agency. Vienna, Austria. 
Newton, T., Hosking, G., Hutton, L., Powney, D., Turland, B., Shuttleworth, T., 2008. Developments within WIMS10, in: Proc. PHYSOR 08, Interlaken, Switzerland.

OECD Nuclear Energy Agency, 1995. Physics of Plutonium Recycling. OECD Publications, Paris, France. Parks, G.T., Knight, M.P., 1995. PWR fuel management using PANTHER, in: Proc. Fuel Management and Handling, Edinburgh, UK. pp. 19-24.

Shwageraus, E., Hejzlar, P., Kazimi, M., 2004a. Use of thorium for transmutation of plutonium and minor actinides in PWRs. Nucl. Technol. 147, 53-68.

Shwageraus, E., Zhao, X., Driscoll, M.J., Hejzlar, P., Kazimi, M.S., 2004b. Microheterogeneous thoria-urania fuels for pressurized water reactors. Nucl. Technol. 147, 20-36.

Zainuddin, N.Z., Parks, G.T., Shwageraus, E., 2016. The factors affecting MTC of thorium-plutonium-fuelled PWRs. Ann. Nucl. Energy submitted. 